University of Nebraska - Lincoln

DigitalCommons@University of Nebraska - Lincoln

Publications from USDA-ARS / UNL Faculty

U.S. Department of Agriculture: Agricultural

Research Service, Lincoln, Nebraska

2005

\title{
Comparative analysis of 87,000 expressed sequence tags from the fumonisin-producing fungus Fusarium verticillioides
}

Daren W. Brown

USDA-ARS, browndw@ncaur.usda.gov

Foo Cheung

The Institute for Genomic Research

Robert $\mathrm{H}$. Proctor

USDA-ARS

Robert A. E. Butchko

USDA-ARS

Li Zheng

The Institute for Genomic Research

See next page for additional authors

Follow this and additional works at: https://digitalcommons.unl.edu/usdaarsfacpub

Brown, Daren W.; Cheung, Foo; Proctor, Robert H.; Butchko, Robert A. E.; Zheng, Li; Lee, Yuandan; Utterback, Teresa; Smith, Shannon; Feldblyum, Tamara; Green, Anthony E.; Plattner, Ronald D.; Kendra, David F.; Town, Christopher D.; and Whitelaw, Catherine A., "Comparative analysis of 87,000 expressed sequence tags from the fumonisin-producing fungus Fusarium verticillioides" (2005). Publications from USDA-ARS / UNL Faculty. 1582.

https://digitalcommons.unl.edu/usdaarsfacpub/1582

This Article is brought to you for free and open access by the U.S. Department of Agriculture: Agricultural Research Service, Lincoln, Nebraska at DigitalCommons@University of Nebraska - Lincoln. It has been accepted for inclusion in Publications from USDA-ARS / UNL Faculty by an authorized administrator of DigitalCommons@University of Nebraska - Lincoln. 


\section{Authors}

Daren W. Brown, Foo Cheung, Robert H. Proctor, Robert A. E. Butchko, Li Zheng, Yuandan Lee, Teresa Utterback, Shannon Smith, Tamara Feldblyum, Anthony E. Green, Ronald D. Plattner, David F. Kendra, Christopher D. Town, and Catherine A. Whitelaw 


\title{
Comparative analysis of 87,000 expressed sequence tags from the fumonisin-producing fungus Fusarium verticillioides
}

\author{
Daren W. Brown ${ }^{\text {a,* }}$, Foo Cheung ${ }^{\mathrm{b}}$, Robert H. Proctor ${ }^{\mathrm{a}}$, Robert A.E. Butchko ${ }^{\mathrm{a}}$, Li Zheng ${ }^{\mathrm{b}}$, \\ Yuandan Lee ${ }^{\mathrm{b}}$, Teresa Utterback ${ }^{\mathrm{c}}$, Shannon Smith ${ }^{\mathrm{c}}$, Tamara Feldblyum ${ }^{\mathrm{c}}$, \\ Anthony E. Glenn ${ }^{\text {d }}$, Ronald D. Plattner ${ }^{\text {a }}$, David F. Kendra ${ }^{\text {a }}$, \\ Christopher D. Town ${ }^{\mathrm{b}}$, Catherine A. Whitelaw ${ }^{\mathrm{b}}$ \\ ${ }^{a}$ Mycotoxin Research Unit, U.S. Department of Agriculture-ARS, Peoria, IL 61604, USA \\ ${ }^{\mathrm{b}}$ The Institute for Genomic Research, 9712 Medical Center Drive, Rockville, MD 20850, USA \\ ${ }^{\mathrm{c}}$ J. Craig Venter Science Foundation Joint Technology Center, 5 Research Place Rockville, MD 20850, USA \\ ${ }^{\mathrm{d}}$ Toxicology and Mycotoxin Research Unit, U.S. Department of Agriculture-ARS, Athens, GA 30605, USA
}

Received 6 January 2005; accepted 6 June 2005

Available online 11 August 2005

\begin{abstract}
Fusarium verticillioides (teleomorph Gibberella moniliformis) is a pathogen of maize worldwide and produces fumonisins, a family of mycotoxins that have been associated with several animal diseases as well as cancer in humans. In this study, we sought to identify fungal genes that affect fumonisin production and/or the plant-fungal interaction. We generated over 87,000 expressed sequence tags from nine different cDNA libraries that correspond to 11,119 unique sequences and are estimated to represent $80 \%$ of the genomic complement of genes. A comparative analysis of the libraries showed that all 15 genes in the fumonisin gene cluster were differentially expressed. In addition, nine candidate fumonisin regulatory genes and a number of genes that may play a role in plant-fungal interaction were identified. Analysis of over $700 \mathrm{FUM}$ gene transcripts from five different libraries provided evidence for transcripts with unspliced introns and spliced introns with alternative $3^{\prime}$ splice sites. The abundance of the alternative splice forms and the frequency with which they were found for genes involved in the biosynthesis of a single family of metabolites as well as their differential expression suggest they may have a biological function. Finally, analysis of an EST that aligns to genomic sequence between FUM12 and FUM13 provided evidence for a previously unidentified gene (FUM20) in the FUM gene cluster.
\end{abstract}

Published by Elsevier Inc.

Keywords: Fusarium verticillioides; Fumonisin; Expressed sequence tag; EST; Regulation; Alternatively spliced isoforms; Secondary metabolite; Gene cluster; FUM20

\section{Introduction}

Fusarium verticillioides (teleomorph Gibberella moniliformis) is a pathogen of maize worldwide and is capable of causing disease of ears, stalks, and seedlings (Munkvold and Desjardins, 1997). During this process, the

\footnotetext{
* Corresponding author. Fax: +1 3096816689.

E-mail address: browndw@ncaur.usda.gov (D.W. Brown).
}

fungus may also synthesize fumonisins, a family of polyketide-derived mycotoxins that are frequently found contaminating maize and are associated with a number of fatal animal diseases, including cancer (Howard et al., 2001). Recently, the association between fumonisins and neural tube birth defects in mice has led to the proposal that fumonisins are a potential risk factor for similar birth defects in humans (Marasas et al., 2004). The biological effects of fumonisin ingestion or exposure are attributed to the disruption of sphingolipid metabolism 
via the inhibition of the enzyme ceramide synthase (Marasas et al., 2004).

Characterization of the biochemical and regulatory pathways leading to fumonisin biosynthesis may lead to novel methods to limit fumonisin contamination of maize. At present, the fumonisin biosynthetic gene $(F U M)^{1}$ cluster consists of 15 co-regulated genes that span $42 \mathrm{~kb}$ of chromosome 1 (Proctor et al., 2003). Predicted amino acid sequence of the FUM cluster genes suggested that 11 genes encode biosynthetic enzymes, two encode transporters, and two encode proteins putatively involved in self-protection (Proctor et al., 2003). A majority of the cluster genes have been functionally characterized and have been found to play a role in fumonisin biosynthesis (Bojja et al., 2004; Butchko et al., 2003a,b; Butchko and Proctor, unpublished observations).

Although most other fungal secondary metabolite gene clusters (e.g., sterigmatocystin/aflatoxin, trichothecene, and lovastatin gene clusters) thus far characterized include pathway-specific regulatory genes (Brown et al., 1996; Hohn et al., 1999; Kennedy et al., 1999; Yu et al., 2004a), sequence analysis of the fumonisin gene cluster did not reveal the presence of a regulatory gene. Two genes that regulate fumonisin biosynthesis and that are not linked to the cluster have been characterized (Flaherty and Woloshuk, 2004; Shim and Woloshuk, 2001). FCC1 encodes a cyclin-like protein that is thought to be part of a signal transduction pathway that affects both fumonisin biosynthesis and development (Shim and Woloshuk, 2001). ZFRI encodes a zinc finger protein that appears to be a positive regulator of $F U M$ genes: fumonisin production was reduced by $90 \%$ compared to wild type in ZFRI deletion mutants (Flaherty and Woloshuk, 2004). A regulatory gene that is solely dedicated to fumonisin biosynthesis has yet to be identified.

Differential expression of messenger RNA has been used extensively to identify genes or gene products involved in specific biological processes. EST studies with $F$. graminearum cDNA libraries identified 2110 genes while expressed sequence tag (EST) studies with Magnaporthe grisea cDNA libraries identified 8177 genes of which some shared identity with pathogenicityassociated genes (Ebbole et al., 2004; Trail et al., 2003). Studies with Aspergillus flavus and microarrays using a selected set of 753 genes differentially expressed during aflatoxin production identified a subset of genes poten-

\footnotetext{
${ }^{1}$ Abbreviations used: EST, expressed sequence tag; NR, nonredundant database; NCBI, National Center for Biotechnology Information; BLAST, basic local alignment search tool; AA, amino acid; ORF, open reading frame; ASF, alternative splice form; TIGR, The Institute for Genomic Research; TGICL, TIGR Gene Indices clustering tools; FUM\#p, fumonisin protein; TC, tentative consensus sequence.
}

tially involved in secondary metabolism or aflatoxin production (OBrian et al., 2003). In this study, we generated over 87,000 ESTs from nine different cDNA libraries to identify candidate genes involved in fumonisin regulation as well as candidate genes important for the plantfungal interaction.

\section{Materials and methods}

\section{1. $c D N A$ library construction}

Total RNA from $F$. verticillioides was purified with TRIzol Reagent (Invitrogen, Carlsbad, CA, USA) following the protocol described by the manufacturer for samples with high polysaccharide content. For libraries prepared from growth in liquid media (Table 1), cultures were vacuum filtered and the resulting mycelial mats were frozen in liquid nitrogen, ground to a powder, and then added to TRIzol at $\approx 1 \mathrm{~g}$ mycelia per $10 \mathrm{ml}$ TRIzol. For libraries prepared from growth on solid media (e.g., maize meal, maize seedling tissue, or developing kernels; Table 1), both the medium and the $F$. verticillioides mycelia were frozen in liquid nitrogen, ground to a powder, and then added to TRIzol at $\approx 1$ g ground material per $10 \mathrm{ml}$ TRIzol. Messenger RNA was isolated from total RNA with the Poly(A)Purist MAG RNA Purification Kit (Ambion, Austin, TX). All libraries were prepared in the pBlueScript II SK(+) XR vector from purified mRNA with the cDNA Synthesis Kit (Stratagene, La Jolla, CA). Libraries FvF and FvG were prepared from RNA obtained from strain M-3125 grown in liquid GYAM ( $8 \mathrm{mM}$ L-asparagine, $1.7 \mathrm{mM} \mathrm{NaCl}, 4.4 \mathrm{mM} \mathrm{K}_{2} \mathrm{HPO}_{4}$, $2 \mathrm{mM} \mathrm{MgSO}_{4}, 8.8 \mathrm{mM} \mathrm{CaCl}_{2}, 0.05 \%$ yeast extract, $0.24 \mathrm{M}$ glucose, and $5.0 \mathrm{mM}$ malic acid) medium for 24 and $96 \mathrm{~h}$, respectively. Library FvM was prepared from pooled RNA obtained from a 48- and 72-h liquid GYAM culture from strain M-3125. Library FvO was prepared from a 90-h liquid GYAM culture from the fumonisin-nonproducing strain 57-7-7 (Desjardins et al., 1996) by the same procedures described above. Library FvN was obtained from RNA derived from a corn meal medium culture of strain M-3125. These cultures were prepared by inoculating an autoclaved mixture of $25 \mathrm{~g}$ corn meal and $5 \mathrm{ml}$ distilled water with $5 \mathrm{ml}$ water containing $5 \times 10^{7}$ conidia. The inoculated medium was mixed thoroughly, distributed equally into two $100-\mathrm{mm}$ plastic petri dishes, and incubated at room temperature for 4 or 6 days. Library FvH was prepared from germinating conidia of strain M-3125 in an aqueous extract of maize seedlings. The aqueous extract was obtained by germinating surface-sterilized maize seeds for 4 days on $1 \%$ water agar supplemented with $100 \mu \mathrm{g} / \mathrm{ml}$ streptomycin sulfate. Under sterile conditions, $70 \mathrm{~g}$ of excised roots and shoots from the 
Table 1

Libraries, culture conditions, and sequencing statistics for ESTs generated in this study

\begin{tabular}{|c|c|c|c|c|c|}
\hline Library ID & Description & TIGR Cat \# & $\begin{array}{l}\text { ESTs } \\
\text { generated }^{\mathrm{a}}\end{array}$ & $\begin{array}{l}\text { Unique } \\
\text { sequences }^{b}\end{array}$ & $\begin{array}{l}\text { Average } \\
\text { read length (bp) }\end{array}$ \\
\hline $\mathrm{FvF}_{\mathrm{v}}$ & Growth for $24 \mathrm{~h}$ in GYAM media & T10964 & 7,647 & 2951 & 636 \\
\hline FvG & Growth for $96 \mathrm{~h}$ in GYAM media & T11287 & 9,120 & 2983 & 655 \\
\hline $\mathrm{FvH}$ & $\begin{array}{l}\text { Growth for } 10 \mathrm{~h} \text { in water extracts } \\
\text { of maize seedlings }\end{array}$ & T11852 & 9,603 & 3114 & 654 \\
\hline \multirow[t]{2}{*}{ FvI } & $\begin{array}{l}\text { Growth on excised maize seedling } \\
\text { roots and shoots }\end{array}$ & $\mathrm{T} 12440$ & 10,953 & 4445 & 679 \\
\hline & & T13474 & & & \\
\hline FvJ & Growth on developing maize kernels & T12441 & 156 & 139 & 632 \\
\hline \multirow[t]{2}{*}{ FvKL } & BOA subtracted library; Ligation 1 and 2 & T12984 & 191 & 58 & 484 \\
\hline & & T12985 & 156 & 47 & 476 \\
\hline FvM & Growth for 48 and $72 \mathrm{~h}$ in GYAM media & T13047 & 12,861 & 2669 & 846 \\
\hline FvN & $\begin{array}{l}\text { Growth on corn meal medium for } \\
4 \text { and } 6 \text { days }\end{array}$ & $\mathrm{T} 14017$ & 17,648 & 4353 & 812 \\
\hline $\mathrm{FvO}$ & $\begin{array}{l}\text { Fumonisin minus strain grown for } \\
90 \mathrm{~h} \text { in GYAM media }\end{array}$ & T14018 & 18,093 & 3534 & 803 \\
\hline
\end{tabular}

a Total number of ESTs generated by sequence analysis of clones from each cDNA library.

b Number of unique sequences (TCs and singletons) within individual library.

resulting seedlings was blended with $250 \mathrm{ml}$ water, filtered once through Miracloth (Calbiochem), and then again through Whatman \#1 filter paper. The extracts were inoculated to a spore concentration of $5 \times 10^{6}$ conidia $/ \mathrm{ml}$ and then incubated for $10 \mathrm{~h}$ at $30^{\circ} \mathrm{C}$ with shaking at 200 RPM. Library FvI was prepared from growth of strain M-3125 on excised maize seedling roots and shoots. The roots and shoots were prepared as described above and then inoculated by dipping briefly in a suspension of $5 \times 10^{6}$ conidia $/ \mathrm{ml}$. The inoculated roots and shoots were then incubated on moistened Whatman \#1 filter paper at room temperature under sterile conditions for 4 days. Libraries FvK and FvL, referred to hereafter after as library FvKL, were constructed employing suppression subtractive hybridization (SSH) based on the PCR Select cDNA Subtraction Kit (Clonetech, USA). These libraries were created to specifically identify $F$. verticillioides genes up-regulated in response to maize antimicrobial defense compounds (Glenn et al., 2001, 2002) and will be described in detail separately.

\subsection{Sequencing methodology and EST clustering}

Plasmid DNA was prepared using the 5-Prime DNA Purification Workstation (Eppendorf-5 Prime, Boulder, CO) and sequenced using Big Dye Terminator Cycle Sequencing Ready Reaction reagents and ABI 3700 or 3730xl Genetic Analyzers (Applied Biosystems, Foster City, CA, USA). Following electrophoresis and fluorescence detection, quality values were assigned to each base call by TraceTuner software (Paracel, Pasadena, CA, USA), and Lucy (Chou and Holmes, 2001) was used to automatically process the raw sequence data, including trimming of low quality bases, vector and Escherichia coli sequences, and those sequences
$<100$ basepairs (bp). ESTs were grouped into clusters using sequence similarity and clone links and the TGICL clustering utilities (Pertea et al., 2003). Each cluster was assembled at high stringency using the Paracel Transcript Assembler (Paracel) to produce tentative consensus sequences (TCs). Those ESTs that did not assemble into a TC were termed "singletons."

\subsection{Sequence analysis}

EST libraries were compared with each other using the TIGR Library Expression Search tool (LES) located within the $F$. verticillioides Gene Index web pages (http:// www.tigr.org/tdb/tgi/). This tool compares ESTs from two or more libraries and generates a list of all sequences with a significant value $(R)$ that is a measure of the likelihood that differences in EST abundance in different libraries are due to differences in the level of gene expression rather than to random sampling (Stekel et al., 2000). Sequences with $R$ values $>9$, a value expected to produce a false positive rate of 1 in 1000, were examined further. Sequence similarity searches of the nonredundant (NR) database maintained by the National Center for Biotechnology Information (NCBI) were performed using BLAST (Altschul et al., 1997; Zhang et al., 1998). Lower $E$ values reflect a higher probability that the assigned function indicated in the tables may be correct. Sequence data from this article have been deposited with the GenBank Data Library under Accession Nos. DR595215DR681653.

\subsection{RT-PCR of FUM14}

Reverse transcription was carried out with SuperScript Reverse Transcriptase (Invitrogen) and primer 728 (5'-TCGAATCGTCCGCTTCACCAGT-3') according 
to the specifications of the manufacturer. PCR was carried out with Taq DNA polymerase (Qiagen), and primers 728 and 727 (5'-GTCAAAGCCATCCAACTCTTATC-3').

\section{Results and discussion}

\subsection{Sequence and library quality}

Nine $F$. verticillioides cDNA libraries were generated from eight different growth conditions for this study (Table 1). A total of 115,657 sequencing reactions of cDNA clones were performed and, after quality assessment, 87,138 ESTs, with an average edited read length of $744 \mathrm{bp}$, were generated. All libraries sequenced with an average success rate of $>80 \%$ except for libraries $\mathrm{FvJ}$ $(61 \%)$ and FvKL (17\%). Library FvKL was prepared by subtractive hybridization and probably sequenced poorly due to the small size of many of the cDNA inserts produced by the subtraction process as sequence reads $<100$ nts were automatically excluded by the quality control software. It is not clear why FvJ sequenced poorly. Due to the low success rate of these libraries, they were not sequenced extensively. Preliminary assessment of cDNAs from each library indicated that FvI and $\mathrm{FVJ}$ contained a significant number of maize cDNA clones. Based on this observation, all FvI and FvJ ESTs were screened against the TIGR maize Gene Index and those with $>95 \%$ nucleotide identity over $95 \%$ of the sequence length were removed. The $F$. verticillioides ESTs from this project and sequences extracted from GenBank were clustered into 7198 TC sequences and 3928 singleton sequences and ETs (Expressed or nonhuman Transcripts from TIGR's Expressed Gene Anatomy Database (EGAD)) to produce a Gene Index of 11,126 unique sequences (www.tigr.org/tdb/tgi/) (Pertea et al., 2003; Quackenbush et al., 2001, 2000) (Table 1).

Initial analyses of the EST data revealed that many ESTs did not occur in all cDNA libraries indicating that the libraries included differentially expressed sequences. The observation that 6048 TCs and singletons were derived from only one of the nine libraries suggests that they may correspond to genes that were expressed under one culture condition but not others (Table 2). In contrast, 1130 TCs consisted of ESTs derived from four or more cDNA libraries and 16 TCs consisted of ESTs from seven libraries (Table 3). The three TCs resulting from the largest number of cDNAs were TC26125 (722), TC29728 (611), and TC26141 (379), and ESTs were present in all libraries except FvJ and FvKL. TC26125 was most similar to DNA damage-responsive protein 48 from Saccharomyces cerevisiae, TC29728 was most similar to elongation factor $1-\alpha$, and TC26141 was most similar to glyceraldehyde 3-phosphate dehydrogenase. The sequences generated in this study were assigned a putative function based on the best hit to a non-redundant
Table 2

Number of library-specific unique sequences

\begin{tabular}{lcrc}
\hline Library ID & Singletons $^{\mathrm{a}}$ & TCs & Total sequences \\
\hline FvF & 516 & 137 & 653 \\
FvG & 375 & 198 & 573 \\
FvH & 416 & 215 & 631 \\
FvI & 1127 & 465 & 1592 \\
FvJ & 66 & 7 & 73 \\
FvKL & 22 & 2 & 24 \\
FvM & 282 & 179 & 461 \\
FvN & 829 & 367 & 1196 \\
FvO & 527 & 318 & 845 \\
Total & 4160 & 1888 & 6048
\end{tabular}

${ }^{\text {a }}$ TCs arising from reads from opposite ends of the same clone were considered singletons for this analysis.

Table 3

Number of TCs that occur in libraries

\begin{tabular}{lc}
\hline Libraries represented $^{\mathrm{a}}$ & No. of TCs \\
\hline 1 & 1888 \\
2 & 1944 \\
3 & 1885 \\
4 & 492 \\
5 & 353 \\
6 & 269 \\
7 & 16 \\
\hline
\end{tabular}

a Number of different libraries in which ESTs for specific TCs were observed. For example, 1888 TCs were derived from ESTs from one library where 1944 TCs were derived from ESTs from two libraries.

b TCs arising from reads from opposite ends of the same clone have been excluded from this analysis.

GO_PEP database using DPS (a DNA alignment program) with a cutoff threshold score of 300 (Huang et al., 1997). Almost $87 \%$ of the unique sequences had a protein hit and 19\% could be assigned to a functional classification based on the Gene Ontology assignments (Ashburner et al., 2000).

To estimate how well the ESTs represent genome coding capacity, we compared the 11,126 sequences in the Gene Index to a $43-\mathrm{kb}$ region of $F$. verticillioides genomic sequence not linked to the fumonisin gene cluster. Initial characterization of the genomic sequence by BLASTX had identified 13 putative genes. In contrast, 16 potential genes were identified by comparison with the Gene Index. Twelve of the 13 genes identified by BLASTX matched the genes identified by the ESTs. A total of four additional genes were identified in the genomic sequence. The predicted function of most of the genes (e.g., glutamine synthetase, $g l s A$; methylcitrate synthase, $m c s A$; isocitrate synthase, ics $A$ ) as well as their occurrence in multiple libraries suggest that they are involved in general housekeeping functions. Only one of the 13 predicted genes was not represented in the EST collection. This analysis indicates that the EST collection represents a high percentage of the $F$. verticillioides coding capacity. 
Table 4

Library expression search (LES) of fumonisin production libraries

\begin{tabular}{lcllc}
\hline LES comparison & Total DE & Fumonisin ${ }^{\text {b }}$ & FUM genes & Possible regulatory \\
\hline FvF vs. FvG & 55 & 12 in FvG & 8 & 1 \\
FvF vs. FvM & 84 & 22 in FvM & $8^{\text {c }}$ & 3 \\
FvM vs. FvF/FvG & 183 & 38 in FvM & 0 & 4 \\
FvG vs. FvF/FvM & 179 & 10 in FvG & 0 & 5 \\
\hline
\end{tabular}

${ }^{a}$ Total number of putatively differentially expressed (DE) genes with $R>9$.

b Number of DE genes observed in the library generated from culture conditions where fumonisins were produced.

c Over all, a total of 10 different $F U M$ genes were detected. Two FUM genes were detected in the FvF vs. FvG comparison that were not detected in the FvF vs. FvM comparison and two FUM genes were detected in the FvF vs. FvM comparison that were not detected in the FvF vs. FvG comparison.

\subsection{Confirmation of the presence of FUM genes in the EST libraries}

In a previous study, $F U M$ gene transcripts were shown to be differentially expressed over time in liquid GYAM cultures of $F$. verticillioides (Proctor et al., 2003). FUM gene transcripts were not detected at $24 \mathrm{~h}$, prior to detection of fumonisins, but were detected in abundance at 88 and $100 \mathrm{~h}$, when fumonisin production was detected. We reasoned that comparisons of ESTs from the libraries prepared from GYAM cultures harvested at different time points could identify differentially expressed transcripts that are important for fumonisin biosynthesis. In this study, fumonisins were not detected in the 24-h culture, low levels of fumonisin $B_{1}(<10 \mu \mathrm{g} /$ $\mathrm{ml}$ ) were detected in the 48- and 72-h cultures, and higher levels $(>50 \mu \mathrm{g} / \mathrm{ml})$ were detected in the $96-\mathrm{h}$ culture. Comparisons among 24-h (FvF), 48/72-h (FvM), and 96-h (FvG) libraries using Gene Index LES tool revealed differential expression of 10 of the 15 FUM cluster genes that correlated with fumonisin biosynthesis (Table 4).

Since LES identifies differentially expressed genes but not genes that are simply expressed, we used the Sequencher (version 4.1.4) assemble function to further explore the occurrence of FUM genes in libraries FvF, FvM, and
FvG. For this analysis, the entire Gene Index was assembled with $42.3 \mathrm{~kb}$ of $F$. verticillioides genomic sequence (Accession No. AF155773) that contains the FUM cluster (Fig. 1). All $10 F U M$ gene TCs detected in the LES analysis as well as TCs and singleton ESTs corresponding to the remaining five $F U M$ genes were detected in this analysis. Overall expression levels, as measured by the percent total of all $15 F U M$ gene ESTs in each library, increased 2.2-fold between 48/72 h (FvM) and $96 \mathrm{~h}(\mathrm{FvG})$ of growth in GYAM (Table 5). The greatest increase in EST abundance (12-fold) was observed for FUM1, which encodes the polyketide synthase thought to catalyze the first step in fumonisin biosynthesis. The failure to detect the differential expression of five $F U M$ genes by LES most likely reflects the limited abundance of ESTs corresponding to these genes. The finding that $F U M$ transcripts were present at or after $48 \mathrm{~h}$ of growth is consistent with previous Northern analyses (Proctor et al., 2003) that revealed the differential expression of $F U M$ genes over time in GYAM.

\subsection{Identification of potential fumonisin regulatory genes}

Two-library LES comparisons between the GYAM libraries also identified a number of putatively differentially expressed genes that may play a role in fumonisin

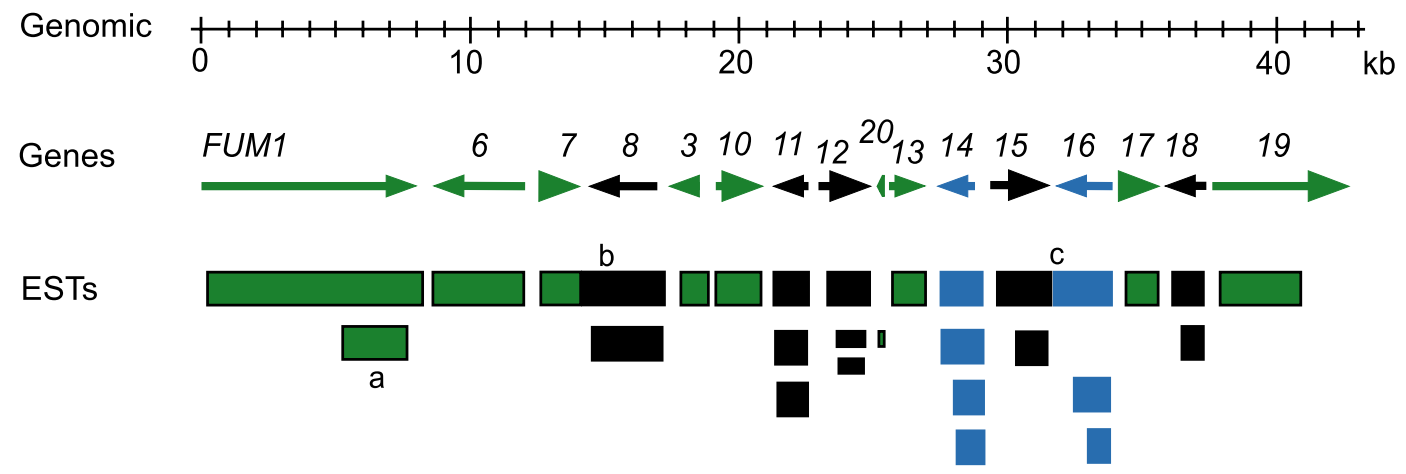

Fig. 1. Comparison of ESTs with the F. verticillioides genomic sequence containing the fumonisin 15-gene cluster. Relative scale is shown in kilobases. Organization of the predicted ORFs. Gene names are indicated above each large arrow. Arrowheads refer to the direction of gene transcription. All boxes represent TCs except for the two boxes under FUM12 and the box under FUM20 that represents singletons. Black boxes/arrows indicate TCs with alternative spliced form transcripts with retained introns and blue boxes/arrows indicate TCs with alternative spliced form transcripts with introns with alternative $3^{\prime}$ borders. (a) TC26329 identified a new intron in FUM1. (b) TC29823 contains ESTs for both FUM7 and FUM8. (c) TC26133 contains ESTs for both FUM15 and FUM16. 
Table 5

Description of FUM genes and distribution of ESTs in GYAM culture-derived libraries ${ }^{\mathrm{a}}$

\begin{tabular}{|c|c|c|c|c|c|c|c|c|}
\hline Gene & Putative function & $\begin{array}{l}\text { Predicted } \\
\text { No. AAs }\end{array}$ & $\begin{array}{l}\text { Total No. } \\
\text { of ESTs }\end{array}$ & $\begin{array}{l}\text { No. ESTs } \\
\text { in FvF }\end{array}$ & $\begin{array}{l}\text { No. ESTs } \\
\text { FvM }^{\mathrm{b}}\end{array}$ & $\begin{array}{l}\text { No. ESTs } \\
\text { FvG }^{\text {b }}\end{array}$ & $\begin{array}{l}\text { Change in } \\
\text { ESTs FvM } \\
\text { to FvG }\end{array}$ & $\begin{array}{l}\text { Change in } \% \\
\mathrm{TO}^{\mathrm{c}} \mathrm{FvM} \\
\text { to FvG }\end{array}$ \\
\hline FUM1 & Polyketide synthase & $2586^{\mathrm{d}}$ & 41 & 0 & 1 & 11 & $12.0 \uparrow$ & \\
\hline$F U M 6^{\mathrm{e}}$ & Cytochrome P450 monooxygenase & 1115 & 44 & 0 & 19 & 13 & No change & \\
\hline$F U M 7^{\mathrm{e}, \mathrm{f}}$ & Dehydrogenase & 424 & 17 & 0 & 11 & 4 & $2.0 \downarrow$ & \\
\hline$F U M 8^{\mathrm{e}, \mathrm{f}}$ & Oxoamine synthase & $836^{\mathrm{d}}$ & 65 & 0 & 16 & 36 & $3.3 \uparrow$ & \\
\hline FUM9 & Dioxygenase & 300 & 41 & 0 & 9 & 17 & $2.7 \uparrow$ & \\
\hline$F U M 10^{\mathrm{f}}$ & Fatty acyl-CoA synthetase & $552^{\mathrm{d}}$ & 91 & 0 & 20 & 61 & $4.5 \uparrow$ & \\
\hline FUM11 & Tricarboxylate transporter & $306^{\mathrm{d}}$ & 19 & 0 & $\begin{array}{r}5 \\
2 \mathrm{TO}\end{array}$ & $\begin{array}{r}7 \\
7 \mathrm{TO}\end{array}$ & $2.0 \uparrow$ & $2.5 \uparrow$ \\
\hline$F U M 12^{\mathrm{e}}$ & Cytochrome P450 monooxygenase & $502^{\mathrm{d}}$ & 85 & 0 & 17 & 63 & $5.4 \uparrow$ & \\
\hline FUM20 & Unknown & na & 1 & 0 & 0 & 1 & & \\
\hline$F U M 13^{\mathrm{e}}$ & Reductase & 369 & 40 & 0 & 20 & 10 & $1.4 \downarrow$ & \\
\hline$F U M 14^{\mathrm{e}}$ & AA condensation domain & $553^{\mathrm{d}}$ & 150 & 0 & $\begin{array}{r}55 \\
1 \mathrm{TO}\end{array}$ & $\begin{array}{r}65 \\
11 \mathrm{TO}\end{array}$ & $1.7 \uparrow$ & $8.9 \uparrow$ \\
\hline$F U M 15^{\mathrm{e}, \mathrm{g}}$ & Cytochrome P450 monooxygenase & $596^{\mathrm{d}}$ & 21 & 0 & 8 & 10 & $1.8 \uparrow$ & \\
\hline$F U M 16^{\mathrm{e}, \mathrm{g}}$ & Fatty acyl-CoA synthetase & $676^{\mathrm{d}}$ & 90 & 0 & $\begin{array}{r}46 \\
10 \mathrm{TO}\end{array}$ & $\begin{array}{r}37 \\
24 \mathrm{TO}\end{array}$ & $1.1 \uparrow$ & $2.7 \uparrow$ \\
\hline FUM17 & Longevity assurance factor & 388 & 6 & 0 & 0 & 3 & & \\
\hline FUM18 & Longevity assurance factor & $384^{\mathrm{d}}$ & 9 & 0 & $\begin{array}{r}5 \\
1 \mathrm{TO}\end{array}$ & $\begin{array}{r}3 \\
2 \mathrm{TO}\end{array}$ & $1.3 \downarrow$ & $3.3 \uparrow$ \\
\hline FUM19 & $\mathrm{ABC}$ transporter & 1489 & 1 & 0 & 0 & 1 & & \\
\hline Total & & & & & 232 & 342 & $2.2 \uparrow$ & $4.4 \uparrow$ \\
\hline
\end{tabular}

${ }^{a}$ FvO FUM transcripts were not considered since there were only four.

b The percent of all ESTs that correspond to FUM genes in FvM was 1.7 (13,315 ESTs) and in FvG was 3.7 (9172 ESTs).

c TO, truncated ORF transcript.

${ }^{\mathrm{d}}$ Updated predicted protein sequence (Accession No. AF155773).

${ }^{\mathrm{e}}$ Genes differentially expressed as identified by LES when compared with FvF.

${ }^{\mathrm{f}}$ Transcripts to FUM7 and FUM8 were assembled into TC29823.

g Transcripts to FUM15 and FUM16 were assembled into TC26133. The potential functionality of four FUM16 transcripts could not be assessed based on available sequence.

${ }^{\mathrm{h}}$ Change calculated as fold difference in number of transcripts observed between FvM and FvG.

biosynthesis (Table 4). In addition to the $F U M$ genes, the $\mathrm{FvF} / \mathrm{FvG}$ comparison identified four FvG-specific TCs one of which shared similarity to a putative regulatory gene: TC30021 shared similarity with the portion of the Homo sapiens EST1A gene (Accession No. AAO17581) that encodes a domain thought to be involved in mRNA decay. The FvF/FvM comparison identified 14 TCs, in addition to the FUM genes, that occurred only in FvM. Ten of these share similarity to genes with known functions $\left(E<10^{-5}\right)$, and three of these (TC30131, TC26574, and TC26727) share similarity to genes encoding known regulatory proteins and therefore have the potential to be involved in the regulation of fumonisin biosynthesis (Table 6).

Although the three-library LES comparisons among FvF, FvM, and FvG did not identify any additional FUM genes, a number of TCs were found that were specific to FvM or FvG that may play a role in fumonisin biosynthesis. For example, the comparison of FvM with FvF and FvG libraries combined identified 183 putatively differentially expressed TCs, 38 of which were present only in FvM (Table 4). Twenty-eight of the 38 are similar $\left(E<10^{-5}\right)$ to genes with known functions. Five of these (TC26530, TC26635, TC30015, TC30558, and TC30268) are similar to genes involved in different aspects of regulation (Table 6). The comparison of FvG with FvF and FvM combined identified 179 putatively differentially expressed TCs, 10 of which were present only in FvG (Table 4). Five of the 10 share significant similarity $\left(E<10^{-5}\right)$ with genes with known function but none to genes with a known regulatory function. It is possible that one or more of the five other FvG-specific genes, which are not similar to any genes with known functions, could be involved in fumonisin regulation. Understanding the role, if any, these genes play in fumonisin biosynthesis will require further analysis.

\subsection{Alternatively spliced forms (ASFs)}

The comparison of the ESTs to the FUM cluster sequence also indicated that some $F U M$ genes matched multiple TCs that differed only by likely intron sequence(s). For example, TCs TC30353, TC30354, and 
Table 6

TCs that correspond to putative fumonisin biosynthetic regulatory genes based on their differential occurrence in libraries FvF, FvG, and FvM

\begin{tabular}{|c|c|c|c|c|c|}
\hline $\mathrm{TC}$ & BLAST homology ${ }^{a}$ & Accession No. & $E$ value & $\mathrm{F}$ or $\mathrm{G}^{\mathrm{b}}$ & M \\
\hline 30131 & Replication factor $\mathrm{C}$ gene & CAA07618 & $3 \times 10^{-97}$ & 2 & 20 \\
\hline 26574 & Src Homology 3 gene & CAE47916 & $2 \times 10^{-19}$ & 0 & 18 \\
\hline 26727 & Zinc-binding transcription factor & AAO64397 & $1 \times 10^{-07}$ & 0 & 21 \\
\hline 26530 & Elongation factor-2 kinase & NP_037434 & $7 \times 10^{-22}$ & 0 & 19 \\
\hline 26635 & Activating transcription factor 4 (ATF-4) & NP_990211 & $6 \times 10^{-07}$ & 0 & 17 \\
\hline 30015 & Ubiquitination/deubiquitination factor & AAO26698 & $7 \times 10^{-72}$ & 0 & 17 \\
\hline 30558 & Frequency clock protein (frq) & T42013 & $4 \times 10^{-86}$ & 0 & 13 \\
\hline 30268 & Molecular chaperone; assists protein folding & NP_036205 & 0.0 & 0 & 11 \\
\hline
\end{tabular}

a TC sequences were BLASTX searched against the NCBI-NR database and the hit with the best $E$ (expected) value is listed. Lower $E$ values reflect a higher probability that the function of the protein encoded by the TC is similar.

b Letters refer to specific library (i.e., F = Library FvF). The number indicates the number of ESTs that comprise each TC from the indicated library.

TC30355 all align to FUM11. The initial description of FUM11 indicated that it had four introns (Proctor et al., 2003). Sequences corresponding to these introns were absent from TC30354 indicating that the intron sequences were spliced out of the corresponding transcripts. In contrast, sequences for the first FUM11 intron were present in TC30353 and TC30355, indicating that the intron was not spliced. Likewise, the sequence corresponding to the third FUMII intron is present in TC30355 (Fig. 2).

To further explore FUM gene ASFs in F. verticillioides, we examined all the FUM ESTs (>700 ESTs) from all libraries (Table 5). ESTs from most FUM genes were present in three libraries: 232 in FvM, 342 in FvG, and 137 in FvN. There are 40 predicted introns in 12 of the 15 FUM genes. The FUM gene ESTs span 35 of these introns for an average of 22.4 ESTs per intron. The coverage ranges from a minimum of once (i.e., the third and fourth FUM19 introns) to a maximum of 94 (i.e., the fourth FUM14 intron). Examination of the 15 FUM gene EST sets revealed ASFs for seven $F U M$ genes, where at least one intron had been retained or had an alternative $3^{\prime}$ border(s) (Table 7 and Fig. 3). The vast majority of ASFs are unlikely to encode full-length proteins because they contain stop codons and/or frame shifts in the coding sequence.

To confirm the presence of ASFs in mRNA, we carried out RT-PCR with primers 727 and 728 , which were expected to amplify a fragment that spanned the third intron of FUM14. Electrophoretic and sequence analysis of the RT-PCR product revealed the presence of two fragments. The first was $186 \mathrm{bp}$ in length and consisted of the expected fragment that lacked the sequence corresponding to the third intron sequence. The second fragment was $245 \mathrm{bp}$ in length and was identical to the first except that it included the 59-bp sequence for the third intron. The detection of FUM14 transcripts with a nonexcised third intron in mRNA is consistent with the EST data.

\subsection{ASF analysis}

Two observations provide circumstantial evidence that the ASFs are not random occurrences of mis-splicing and may serve a function. First is the sheer number and distribution of ASFs. We examined over 700 FUM gene ESTs and found 78 ASFs that corresponded to seven of the 15 FUM genes. For the most part, a normal or correct splice form is any transcript where all possible introns have been excised, whereas ASFs retain one or more introns that introduce a stop codon or a frameshift. The percent ASFs for FUM11, FUM14, FUM16, and $F U M 18$ were $47,11,51$, and $44 \%$ based on 19,134 , 90, and 9 ESTs, respectively, and the percent ASFs for FUM 8 and FUM12 were 3 and $2 \%$ based on 65 and 85 ESTs, respectively. The FUM15 ASFs are unique in that the retention of the third intron in eight of nine ESTs does not interfere with the ORF.

Second, the ASFs were differentially expressed over time. More ASFs were found at $96 \mathrm{~h}(\mathrm{FvG})$ than at $48 /$ $72 \mathrm{~h}(\mathrm{FvM})$ for FUM11, FUM14, FUM16, and FUM18 (Table 5). In the case of $F U M 11$, two of five transcripts at 48/72 h were ASFs (e.g., retained an intron) while all seven transcripts at $96 \mathrm{~h}$ retained an intron. Thus,
$1311 \mathrm{bp}$

1

Genomic Sequence
TC30354
TC30353
TC30355

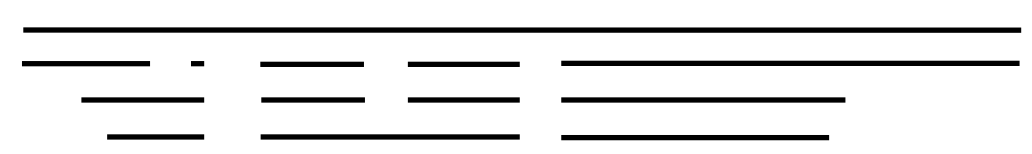

Fig. 2. Diagram of multiple sequence alignment spanning $1310 \mathrm{bp}$ of the FUM11 genomic sequence and three tentative consensus sequences generated during the assembly of the TIGR Gene Index. TC30353 is derived from six ESTs, TC30354 is derived from nine ESTs, and TC30355 is derived from four ESTs. Failure to excise the first intron introduces two stop codons in the predicted protein coding ORF. Each gap represents sequence that is missing from the respective TC. 
Table 7

FUM gene introns, TCs/ESTs, and ASFs

\begin{tabular}{lllcc}
\hline Gene & \# introns & TCs and singletons & $\begin{array}{c}\text { Total } \\
\text { ESTs }\end{array}$ & \% TOs $^{\text {a }}$ \\
\hline FUM1 & 6 & $26328,26329^{\mathrm{b}}$ & 41 & \\
FUM6 & 3 & 26332 & 44 & \\
FUM7 & 0 & $29823^{\mathrm{c}}$ & 17 & \\
FUM 8 & 5 & 29823,29825 & 65 & 3 \\
FUM3 & 0 & 29917 & 41 & \\
FUM10 & 2 & 29844 & 91 & \\
FUM11 & 4 & $30353,30354,30355$ & 19 & 47 \\
FUM12 & 3 & 26246, FVNDE14TV, & 85 & 2 \\
& & FVGAW46TH & & \\
FUM13 & 0 & 29927 & 40 & \\
FUM14 & 4 & $29764,29765,29767,29768$ & 150 & 11 \\
FUM15 & 1 & 26133,26137 & 21 & Note $^{\mathrm{f}}$ \\
FUM16 & 3 & 26133,26134 & 90 & 51 \\
FUM17 & 1 & 26780 & 6 & \\
FUM18 & 4 & 26779,26781 & 9 & 44 \\
FUM19 & 4 & 33164 & 1 & \\
\hline TO & & & &
\end{tabular}

a TO, truncated ORF.

${ }^{b}$ All five ESTs that make up TC26329 identified a newFUM1 intron.

c TC29823 includes EST for both FUM7 and FUM8.

d FVNB289TH and FVNB547TH share partial identity to FUM10 but are artifacts. Only about half of each EST sequence matches well with FUM10 genomic sequence.

e TC29766 shares partial identity to FUM14 but is an artifact. The first $864 \mathrm{bp}$ of this TC is not similar to any sequence in the fumonisin cluster while the last 723 bp shares $98 \%$ identity with FUM14.

${ }^{f}$ The predicted protein from the FUM15 ASF with the intron is 26 AAs longer than the predicted protein from the FUM15 ASF that lacks the intron.

although Northern analysis would suggest that the relative expression of FUMII at the two time points was similar, none of the FUM11 transcripts at $96 \mathrm{~h}$ are capable of generating a full-length protein. Overall, the number of ESTs representing different isoforms (or ASFs) increased 4.4-fold from 48/72 to $96 \mathrm{~h}$. In general, ASFs for other $F$. verticillioides genes do not exhibit similar expression patterns. The TIGR Gene Index identified 247 genes with putative ASFs among 7198 tentative consensus sequences (http://www.tigr.org/tdb/tgi/fungi.shtml). Of 119 clusters that we examined closely, 29 contain ESTs derived from the GYAM medium libraries (FvF, FvM or FvG). Only three of these exhibited a pattern of ASF expression similar to FUM gene ASFs (data not shown). Thus, the pattern of expression for FUM gene ASFs is unusual compared to other ASFs present in the FvF, FvM, and FvG libraries. We are currently in the process of examining the relative occurrence of all FUM gene ASFs under different growth conditions via microarrays. It should also be noted that introns within the same gene were alternatively spliced to different degrees. For example, the first FUM11 intron was processed in all 19 EST sequences that span the intron while the second intron was retained in five of 19 ESTs and the fourth intron was retained in nine of 15 ESTs that span the intron. The significance of this observation is not known.

Alternatively or differentially spliced transcripts can regulate gene expression positively and/or negatively in numerous mammalian systems (Black, 2003). Given this, it is possible that ASFs can regulate gene expression in fungi as well. For example, the transcripts or any resulting truncated proteins could interfere with transcription, translation or protein function. Alternatively, perhaps the non-processed transcripts serve as a reservoir for future translational potential. Intron excision may be delayed by an unknown mechanism and thus serve as a posttranscriptional regulatory control point whereby transcripts capable of generating full-length proteins are limited. In a similar way, the $S$. cerevisiae $H A C l \mathrm{mRNA}$ is constitutively expressed but is not functional until it is spliced (Kawahara et al., 1998). The functional Haclp is

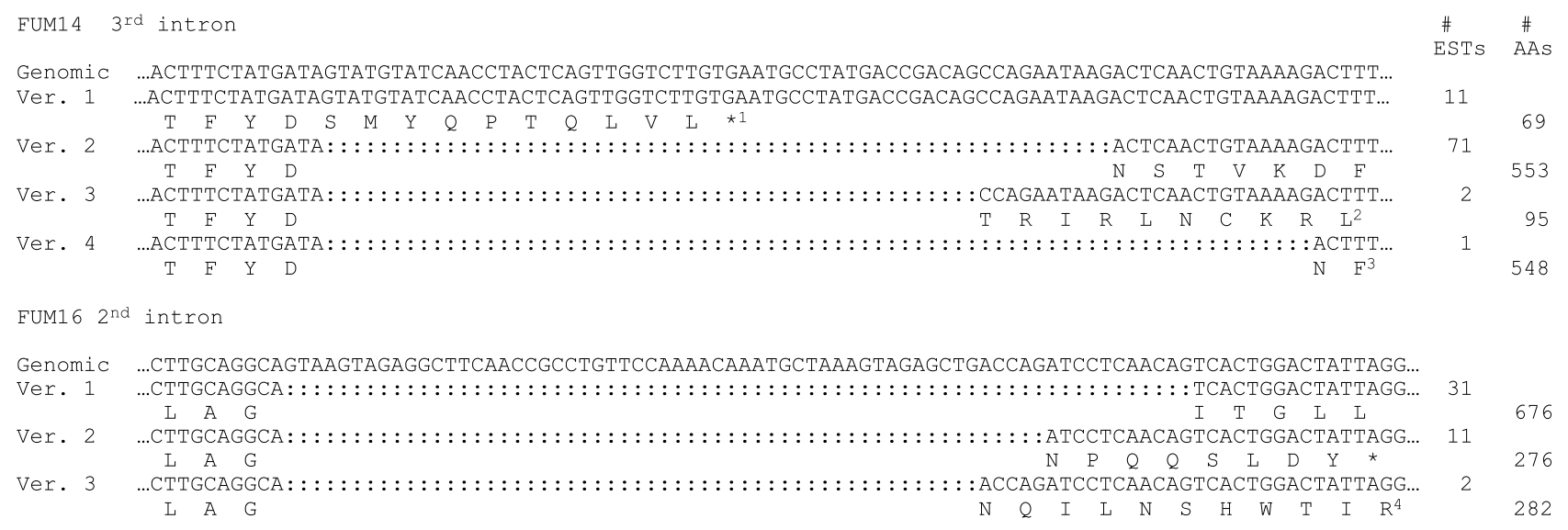

Fig. 3. Differentially spliced FUM14 and FUM16 introns. The predicted amino acid (AA) sequences are indicated below the nucleotide sequences and the total number of predicted AAs is indicated to the right of the AA sequence. The number of ESTs corresponding to each version (ver.) found in the EST libraries is indicated to the right of the sequence. (1) The asterisk refers to a stop codon. (2) The 27th codon following the CTT codon is a stop codon. (3) Amino acids STVKD are predicted to be missing from proteins encoded by FUM14 Ver. 4 transcripts. (4) The fourth codon following the AGG codon is a stop codon. It should be noted that 3' border sequence for the FUM16 Ver. 3 intron is TG rather than the typical AG and was observed in two EST sequences. 
required for the activation of the unfolded protein response in the endoplasmic reticulum. In this example, the $5^{\prime}$ and $3^{\prime}$ splice sites do not match the GT-AG consensus sequences (Kawahara et al., 1998). However, all of the unspliced introns described in our study contain the consensus sequence found in fungi and higher eukaryotes (Brown et al., 2001; Proctor et al., 2003). In contrast to FUM11 and FUM14, it is difficult to speculate why isoforms with incomplete or truncated ORFs for FUM16 and FUM18 accumulate late in culture as neither is required for fumonisin synthesis (Proctor et al., 2003; Proctor and Butchko, unpublished observations).

ASFs have been previously described for a few genes in other fungi but on a very limited basis (Boel et al., 1984; Curach et al., 2004; Larrondo et al., 2004; McColl et al., 2003; Sachs and Yanofsky, 1991; Yadav et al., 2003). In all cases so far, their physiological impact is unknown. In the yeast Xanthophyllomyces dendrorhous, the percentage of ASFs with incomplete ORFs of a gene involved in carotenoid biosynthesis were also found to increase with culture age (Lodato et al., 2003). In contrast to these examples, many genes with ASFs have been found in large scale EST programs described at the TIGR Fungal Gene Indices (http://www.tigr.org/tdb/tgi/fungi.shtml) including 51 in Cryptococcus, 96 in A. flavus, 92 in M. grisea, and 63 in Neurospora crassa. To our knowledge, the function and occurrence of these ASFs have not yet been described in the literature. It is interesting to note that $19 \%$ of the 21 aflatoxin cluster genes found in the A. flavus EST collection had ASFs (Yuet al.,2004b)(http://www.tigr.org/tigr-scripts/ tgi/splnotes .pl?species $=$ a_flavus). Perhaps the role that ASFs play is most significant for genes involved in secondary metabolism.

Although a majority of $F U M$ gene ASFs result in truncated ORFs, some FUM14 and FUM15 ASFs are predicted to encode proteins that differ minimally from those encoded by the majority of transcripts. The synthesis of alternative proteins is a hallmark and a significant consequence of differential intron splicing in higher eukaryotes (Black, 2003). The alternative FUM14 transcript resulting from a different $3^{\prime}$ border for the third FUM14 intron (Fig. 3) could form a protein with five fewer AAs than proteins derived from the major splice form. The five AAs are located at the C-terminal part of the phosphopantetheinebinding domain $\approx 25 \mathrm{AAs}$ from the serine attachment site. Further studies will be required to determine whether this change affects protein function. The alternative FUM15 transcripts resulted from retention of the second intron in eight of nine FUM15 ESTs and would encode a protein with 26 AAs more than the EST with the intron excised. The 26 AAs are located within the variable length K-helix and three AAs from an absolutely conserved sequence ExxR thought to play a critical protein stabilizing role (Pylypenko and Schlichting, 2004). The importance of the variable length is unknown as both predicted proteins match very well to two different conserved domains
(NCBI database pfam00067 and COG2124) associated with different sets of cytochrome P450s (Marchler-Bauer et al., 2005). Determining whether the activity of the alternative Fum $15 p$ form differs from that of the more abundant form will require additional studies.

\subsection{Revised FUM protein predictions}

The 700 plus $F U M$ gene transcripts afforded us the opportunity to reassess the predicted coding region for each FUM gene. Complete coding sequences for each putative $F U M$ gene were predicted based on a combination of similarity with previously characterized proteins, existing ORFs, and presence or absence of intron border sequences (Proctor et al., 2003). A comparison of the FUM gene ESTs to the fumonisin cluster genomic sequence led to the identification of new introns or intron borders in nine of the original 15 genes and enabled us to adjust the predicted protein sequences appropriately (Table 5; Accession No. AF155773). In some cases, predicted protein changes were minimal. For example, the new predicted Fum $12 p$ had nine AAs deleted near the amino terminus, while the new Fum13p had five AAs added. In other cases, the predicted protein changes are more extensive. For example, the new Fum8p had 51 AAs changed within the middle of the protein, whereas Fum10p had 59 AAs added to the carboxy terminus and Fum15p had 20 AAs deleted near the carboxy terminus. These changes could affect functional studies using expressed proteins and the new information will guide subsequent research.

\subsection{Identification of a new FUM gene}

Our approach to sequence the cDNA libraries to significant depth led to the identification of a new FUM gene, designated FUM20, located between FUM12 and FUM13 in the FUM gene cluster (Fig. 1). The first evidence for the existence of this gene came from a comparison of TC26246 with genomic DNA sequence (Accession No. AF155773). The presence of three previously predicted FUM12 introns was confirmed (Proctor et al., 2003) as well as a fourth intron with non-typical border sequences. Analysis of the 87 ESTs that make up TC26246 indicated that the sequence bordering the fourth intron was derived from a single EST, FVGBR83TH, consisting of $680 \mathrm{nts}$ (Fig. 4). The presence of a poly(A) tract in FVGBR83TH indicates a direction of transcription opposite to that of FUM12, and when viewed in this orientation, the intron borders are typical and support the identification of FUM20. The $3^{\prime}$ border for FVGBR83TH includes the predicted FUM12 stop codon and overlaps a number of the FUM12 ESTs by up to $200 \mathrm{nts}$. The $5^{\prime}$ border of FVGBR83TH is $92 \mathrm{nts}$ from the start codon of FUM13 and 43 nts from the end of TC29927 (Fig. 4). 


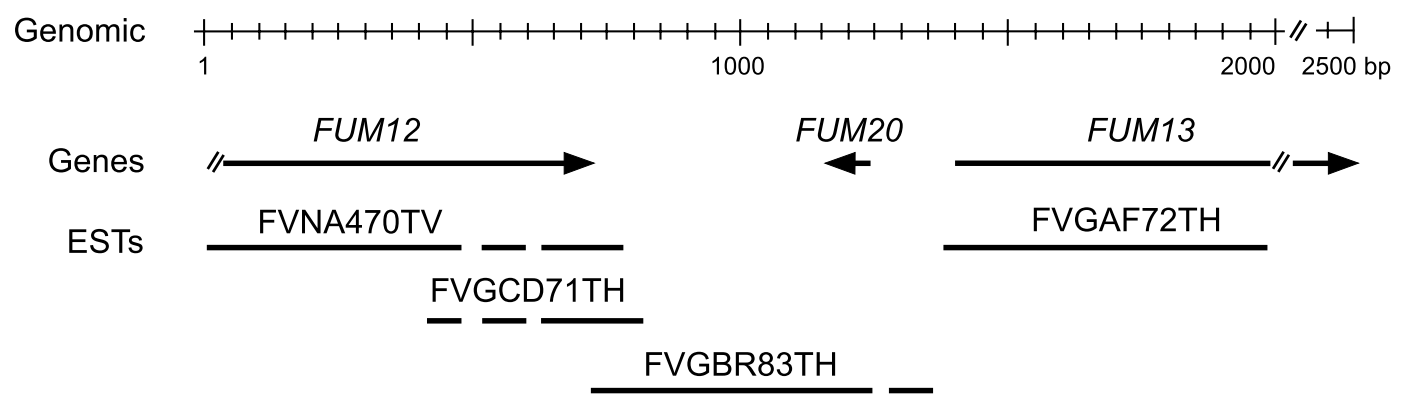

Fig. 4. Discovery of FUM20. Diagram shows gapped alignments of representative ESTs from FUM12 (FVNA470TV, 907 nts, and FVGCD71TH, $670 \mathrm{nts}$ ) and FUM13 (FVGAF72TH, $686 \mathrm{nts}$, and FVGBR83TH, $680 \mathrm{nts}$ ) with $F$. verticillioides genomic sequence within the fumonisin gene cluster. Relative scale is shown in basepairs. Gene names are indicated above each arrow and arrowheads refer to the direction of gene transcription. The gaps in the ESTs sequences indicate introns. The FUM20 ORF could not be determined.

What role, if any, FUM20 plays in fumonisin biosynthesis is not clear. Both BLASTX of FVGBR83TH and BLASTP of the predicted 40-AA FUM20 protein did not suggest a possible function as neither share significant similarity with any previously described genes or proteins in the NCBI-NR database. In addition, TBLASTN of Fum $20 \mathrm{p}$ against the $F$. graminearum genome sequence did not reveal any sequence similarity. It is possible that the FUM20 transcript is an ASF. The excision of additional intron(s) may lead to a predicted protein that shares similarity to proteins with known function. Alternatively, the FUM20 transcript may be non-coding RNA that regulates $F U M$ gene expression. Over-expression and gene deletion studies are underway to help determine the function of FUM20.

\subsection{Maize-tissue induced ESTs}

To identify genes involved in pathogenesis of $F$. verticillioides on maize, we created four cDNA libraries ( FvH, FvI, FvN, and FvJ) from fungal RNA extracted after growth on maize-based media (Table 1). Due to the small number of ESTs in library FvJ, it has limited value. A LES comparison of libraries FvH, FvI, and $\mathrm{FvN}$ with the four GYAM-derived libraries (FvF, FvG, FvM, and
FvO; Table 1) identified 743 differentially expressed TCs $(R>9)$ some of which share similarity with previously recognized fungal virulence genes (Table 8). For example, TC27603 shares significant similarity with a coppertransporting ATPase of Colletotrichum lindemuthianum that is critical for infection (Parisot et al., 2002). In addition, TC31240 shares significant similarity with a chitinbinding protein from the yeast Pichia inositovara that is part of a killer activity toward $S$. cerevisiae (Klassen and Meinhardt, 2003).

There were three differentially expressed TCs that match previously identified $F$. verticillioides hydrophobins and another (TC26886) that shares similarity to a protein (snodprot1) produced by Phaeosphaeria nodorum during infection of wheat leaves and is a member of a family of proteins with hydrophobin-like properties (Pazzagli et al., 1999). The reference protein for the snodprot1 protein family, cerato-platanin, produced by Ceratocystis fimbriata, is phytotoxic (Boddi et al., 2004). Hydrophobins are known to be involved in recognition processes with other organisms and hence likely play an important role in pathogenesis (Ebbole, 1997). Recently, the three hydrophobin genes described above plus two additional hydrophobin genes were disrupted and none were required to cause maize seedling disease

Table 8

Fusarium verticillioides plant-associated genes with similarity to virulence genes from other fungi

\begin{tabular}{|c|c|c|c|c|c|}
\hline $\mathrm{TC}$ & Putative function & Accession No. & $E$ value & $\mathrm{FGMO}^{\mathrm{a}}$ & IH or $\mathrm{N}$ \\
\hline 27603 & Copper-transporting & AAN62846 & 0.0 & 0 & $6 \mathrm{I}, 1 \mathrm{H}$ \\
\hline 31240 & Chitin-binding protein & CAD91890 & $3 \times 10^{-65}$ & $1 \mathrm{~F}$ & $6 \mathrm{H}$ \\
\hline 29850 & Hydrophobin $1^{\mathrm{b}}$ & AY155496 & 0.0 & $1 \mathrm{G}$ & $42 \mathrm{~N}, 27 \mathrm{I}$ \\
\hline 26567 & Hydrophobin 2 & AY155497 & 0.0 & 0 & $27 \mathrm{~N}$ \\
\hline 30113 & Hydrophobin 3 & AY155498 & 0.0 & 10 & $6 \mathrm{I}, 1 \mathrm{H}$ \\
\hline 26886 & Virulence protein & AAC26870 & $1 \times 10^{-38}$ & 0 & $14 \mathrm{~N}, 2 \mathrm{H}$ \\
\hline 30234 & P450 & AAQ16576 & $8 \times 10^{-69}$ & 0 & $12 \mathrm{~N}$ \\
\hline 30242 & P450 & AAQ16576 & $7 \times 10^{-66}$ & 0 & $14 \mathrm{~N}$ \\
\hline 31401 & Terpenoid cyclase & AAQ16575 & $5 \times 10^{-22}$ & 0 & $6 \mathrm{H}$ \\
\hline 27406 & Stress-response factor & NP_014371 & $4 \times 10^{-41}$ & 0 & $7 \mathrm{H}, 2 \mathrm{~N}$ \\
\hline
\end{tabular}

${ }^{a}$ Letters refer to EST libraries, respectively (i.e., $\mathrm{F}=$ library FvF). The number indicates the number of ESTs that comprise each TC from the indicated library (i.e., $6 \mathrm{I}=\mathrm{TC} 27603$ includes six ESTs from library FvI).

b The three $F$. verticillioides hydrophobin genes have previously been described. See text for details. 
(Fuchs et al., 2004). This finding does not preclude the possibility that hydrophobins are required for other maize diseases (e.g., ear rot) caused by $F$. verticillioides.

The LES analysis also detected four differentially expressed TCs (TC30234, TC30242, TC31401, and TC27406) that share similarity to genes (CNDs) regulated through the calcineurin pathway (Table 8). Calcineurin is an essential phosphatase and has been shown to be required for virulence in a number of fungal systems (Viaud et al., 2003). CND5 and CND15 are located adjacent to each other in Botrytis cinerea and are speculated to be involved in the synthesis of a secondary metabolite involved in virulence (Viaud et al., 2003). TC27406 shares significant similarity with a $S$. cerevisiae transcription factor (Crzlp) involved in stress response and whose nuclear localization is positively regulated by calcineurin-mediated dephosphorylation (Philippsen et al., 1997). The exact role of this or any of the potential virulence-associated genes described above in F. verticillioides will be determined by further studies.

\subsection{Comparison of ESTs to three fungal genome sequences}

Fusarium verticillioides is closely related to $F$. graminearum which can also cause ear rot and other maize diseases. BLAST analysis of the $F$. verticillioides ESTs in the Gene Index revealed that $86 \%$ of the ESTs shared significant similarity $\left(E<10^{-5}\right)$ with portions of $F$. graminearum genome sequence and $81 \%$ had significant similarity $\left(E<10^{-5}\right)$ to the $\sim 13,700 \mathrm{~F}$. graminearum genes predicted by the Munich Information Center for Protein Sequences (http://mips.gsf.de/genre/proj/fusarium). On the basis of the likelihood that the number of genes in $F$. graminearum is similar to $F$. verticillioides, the latter comparison suggests that our ESTs represent over $80 \%$ of all possible $F$. verticillioides genes. Experiments are in progress to determine whether some of the genes unique to $F$. verticillioides are involved in aspects of the $F$. verticillioides-maize interaction that differ from the $F$. graminearum-maize interaction.

We also compared the EST sequences against the genomic sequences of the saprophytic (non-pathogenic) fungi Aspergillus nidulans and N. crassa (Fig. 5). As expected, the number of $F$. verticillioides sequences with high levels of similarity to genes from the saprophytes was less than that observed for $F$. graminearum. We then sought to identify unique Fusarium genes that may be critical for these fungi to cause disease. We reasoned that these genes could be identified by taking the set of $F$. verticillioides ESTs most similar to $F$. graminearum $(\approx 2000$ TCs and singletons with a BLASTX threshold $\leqslant 10^{-200}$ ) and removing all those that are shared with Aspergillus or Neurospora ( $E \leqslant 10^{-5}$ in BLASTX). This analysis yielded $39 \mathrm{~F}$. verticillioides ESTs and TCs. Twenty-two of these share similarity to enzyme-encod-

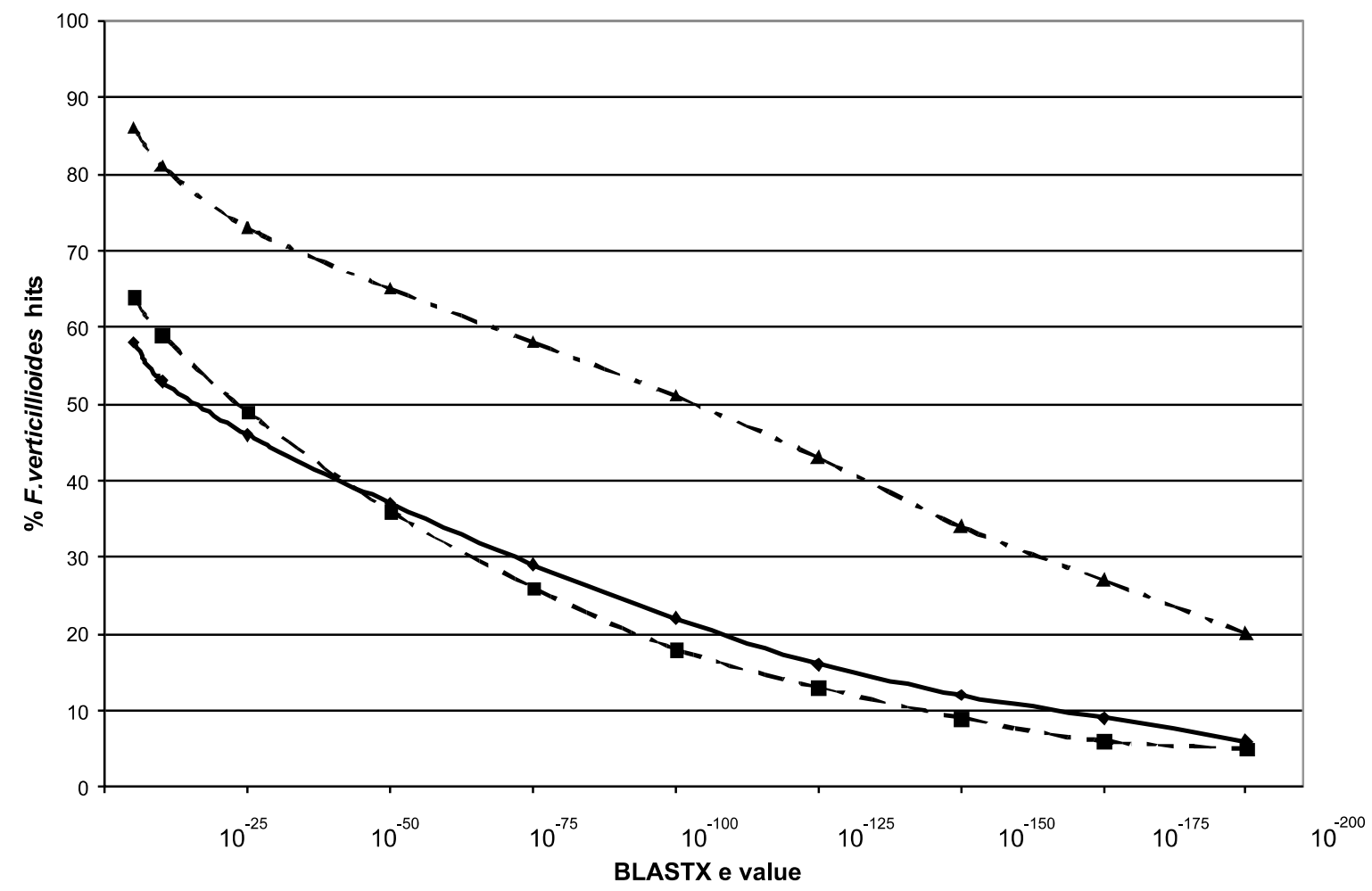

Fig. 5. Comparison of $F$. verticillioides Gene Index sequences against $F$. graminearum $(\boldsymbol{\Lambda},---)$, Aspergillus nidulans ( $\mathbf{\square},---)$, and Neurospora crassa $(\bullet,-)$ protein sequences. Vertical axis represents percent $F$. verticillioides matches and the horizontal axis represents BLASTX $E$ value of the matches. 
ing genes involved in modifications of low molecular weight compounds or proteins (e.g., monooxygenase), and 15 do not share similarity to any previously described genes. The two remaining ESTs share similarity to putative regulatory genes; TC27771 shares similarity with a putative zinc finger protein (NP_594226) from Schizosaccharomyces pombe and TC32201 shares similarity with a gene encoding a WD40 repeat containing protein (ZP_00324864) from Trichodesmium erythraeum. We are in the process of determining whether these two genes are involved in plant pathogenesis by F. verticillioides.

\section{Summary}

Expressed sequence tags are an important tool in defining gene structure and understanding gene expression, transcript splicing, and protein structure, and are a critical complement to whole genome sequence efforts. Recently, 26,110 ESTs generated from an A. flavus normalized cDNA library led to the identification of 7218 putative genes which was estimated to represent $60 \%$ of the predicted genes, encoded by the A. flavus and genome (Yu et al., 2004b). The library was constructed from RNA from eight different media conditions seven of which support aflatoxin production (Yu et al., 2004b). The 87,059 ESTs from our nine cDNA libraries led to 11,119 putative $F$. verticillioides genes which we estimate to represent over $80 \%$ of the predicted genes. Both the $A$. flavus and the $F$. verticillioides collections should contribute significantly to a better understanding of the biology of host-pathogen interactions, and the biochemical and regulatory processes involved in mycotoxin biosynthesis.

An initial goal of our project was to find fumonisin regulatory genes by identifying genes that were differentially expressed genes within the fumonisin production medium (GYAM) libraries. Nine potential fumonisin regulatory genes have been identified and are being further characterized. The abundance and differential expression of ASFs among FUM genes raise the intriguing possibility that the regulation of intron splicing serves a role in fumonisin biosynthesis. Microarray experiments are in progress and may provide evidence to support our model that the FUM transcripts with truncated ORFs impact fumonisin production.

A second goal was to identify fungal genes that are important for the $F$. verticillioides-maize interaction. Numerous ESTs were identified that were differentially expressed by the fungus in the presence of maize material. Comparison of the ESTs to the genome sequence of two saprophytic and another plant pathogenic fungus identified genes that may be involved in the ability of Fusarium species to cause disease. Gene-disruption studies are in progress to determine whether any of these genes are required for toxin production or virulence of $F$. verticillioides on maize.

\section{Acknowledgments}

We thank Dr. Catherine Ronning, The Institute for Genomic Research, for helping to initiate the EST project, the Gene Index group, and Simon Van Heeringen for the development and availability of their EST clustering utilities and assistance with data organization and analysis, and the TIGR information technology and database groups for their support. We thank Marcie Moore, Debbie Shane, and Elizabeth Mays for providing technical assistance.

\section{References}

Altschul, S.F., Madden, T.L., Schaffer, A.A., Zhang, J., Zhang, Z., Miller, W., Lipman, D.J., 1997. Gapped BLAST and PSI-BLAST: a new generation of protein database search programs. Nucleic Acids Res. 25, 3389-3402.

Ashburner, M., Ball, C.A., Blake, J.A., Botstein, D., Butler, H., Cherry, J.M., Davis, A.P., Dolinski, K., Dwight, S.S., Eppig, J.T., Harris, M.A., Hill, D.P., Issel-Tarver, L., Kasarskis, A., Lewis, S., Matese, J.C., Richardson, J.E., Ringwald, M., Rubin, G.M., Sherlock, G., 2000. Gene ontology: tool for the unification of biology. The Gene Ontology Consortium. Nat. Genet. 25, 25-29.

Black, D.L., 2003. Mechanisms of alternative pre-messenger RNA splicing. Annu. Rev. Biochem. 72, 291-336.

Boddi, S., Comparini, C., Calamassi, R., Pazzagli, L., Cappugi, G., Scala, A., 2004. Cerato-platanin protein is located in the cell walls of ascospores, conidia and hyphae of Ceratocystis fimbriata f. sp. platani. FEMS Microbiol. Lett. 233, 341-346.

Boel, E., Hjort, I., Svensson, B., Norris, F., Norris, K.E., Fiil, N.P., 1984. Glucoamylases G1 and G2 from Aspergillus niger are synthesized from two different but closely related mRNAs. EMBO J. 3, 1097-1102.

Bojja, R.S., Cerny, R.L., Proctor, R.H., Du, L., 2004. Determining the biosynthetic sequence in the early steps of the fumonisin pathway by use of three gene-disruption mutants of Fusarium verticillioides. J. Agric. Food Chem. 52, 2855-2860.

Brown, D.W., McCormick, S.P., Alexander, N.J., Proctor, R.H., Desjardins, A.E., 2001. A genetic and biochemical approach to study trichothecene diversity in Fusarium sporotrichioides and Fusarium graminearum. Fungal Gen. Biol. 32, 121-144.

Brown, D.W., Yu, J.-H., Kelkar, H.S., Fernandes, M., Nesbitt, T.C., Keller, N.P., Adams, T.H., Leonard, T.J., 1996. Twenty-five co-regulated transcripts define a sterigmatocystin gene cluster in Aspergillus nidulans. Proc. Natl. Acad. Sci. USA 93, 1418-1422.

Butchko, R.A., Plattner, R.D., Proctor, R.H., 2003a. FUM9 is required for C-5 hydroxylation of fumonisins and complements the meitotically defined Fum3 locus in Gibberella moniliformis. Appl. Environ. Microbiol. 69, 6935-6937.

Butchko, R.A., Plattner, R.D., Proctor, R.H., 2003b. FUM13 encodes a short chain dehydrogenase/reductase required for C-3 carbonyl reduction during fumonisin biosynthesis in Gibberella moniliformis. J. Agric. Food Chem. 51, 3000-3006.

Chou, H.H., Holmes, M.H., 2001. DNA sequence quality trimming and vector removal. Bioinformatics 17, 1093-1104

Curach, N.C., Te'o, V.S., Gibbs, M.D., Bergquist, P.L., Nevalainen, K.M., 2004. Isolation, characterization and expression of the hexl gene from Trichoderma reesei. Gene 331, 133-140. 
Desjardins, A.E., Plattner, R.D., Proctor, R.H., 1996. Linkage among genes responsible for fumonisin biosynthesis in Gibberella fujikuroi mating population A. Appl. Environ. Microbiol. 62, 2571-2576.

Ebbole, D.J., 1997. Hydrophobins and fungal infection of plants and animals. Trends Microbiol. 5, 405-408.

Ebbole, D.J., Jin, Y., Thon, M., Pan, H., Bhattarai, E., Thomas, T., Dean, R., 2004. Gene discovery and gene expression in the rice blast fungus, Magnaporthe grisea: analysis of expressed sequence tags. Mol. Plant Microbe Interact. 17, 1337-1347.

Flaherty, J.E., Woloshuk, C.P., 2004. Regulation of fumonisin biosynthesis in Fusarium verticillioides by a zinc binuclear cluster-type gene, ZFR1. Appl. Environ. Microbiol. 70, 2653-2659.

Fuchs, U., Czymmek, K.J., Sweigard, J.A., 2004. Five hydrophobin genes in Fusarium verticillioides include two required for microconidial chain formation. Fungal Gen. Biol. 41, 852-864.

Glenn, A.E., Gold, S.E., Bacon, C.W., 2002. Fdb1 and Fdb2, Fusarium verticillioides loci necessary for detoxification of preformed antimicrobials from corn. Mol. Plant Microbe Interact. 15, 91-101.

Glenn, A.E., Hinton, D.M., Yates, I.E., Bacon, C.W., 2001. Detoxification of corn antimicrobial compounds as the basis for isolating Fusarium verticillioides and some other Fusarium species from corn. Appl. Environ. Microbiol. 67, 2973-2981.

Hohn, T.M., Krishna, R., Proctor, R.H., 1999. Characterization of a transcriptional activator controlling trichothecene toxin biosynthesis. Fungal Genet. Biol. 26, 224-235.

Howard, P.C., Eppley, R.M., Stack, M.E., Warbritton, A., Voss, K.A., Lorentzen, R.J., Kovach, R.M., Bucci, T.J., 2001. Fumonisin B1 carcinogenicity in a two-year feed study using F344 rats and B6C3F1 mice. Environ. Health Perspect. 109, 277-282

Huang, X., Adams, M.D., Zhou, H., Kerlavage, A.R., 1997. A tool for analyzing and annotating genomic sequences. Genomics 46 , $37-45$.

Kawahara, T., Yanagi, H., Yura, T., Mori, K., 1998. Unconventional splicing of HAC1/ERN4 mRNA required for the unfolded protein response. Sequence-specific and non-sequential cleavage of the splice sites. J. Biol. Chem. 273, 1802-1807.

Kennedy, J., Auclair, K., Kendrew, S.G., Park, C., Vederas, J.C., Hutchinson, C.R., 1999. Modulation of polyketide synthase activity by accessory proteins during lovastatin biosynthesis. Science 284, 1368-1372.

Klassen, R., Meinhardt, F., 2003. Structural and functional analysis of the killer element pPin1-3 from Pichia inositovora. Mol. Genet. Genomics 270, 190-199.

Larrondo, L.F., Gonzalez, B., Cullen, D., Vicuna, R., 2004. Characterization of a multicopper oxidase gene cluster in Phanerochaete chrysosporium and evidence of altered splicing of the mco transcripts. Microbiology 150, 2775-2783.

Lodato, P., Alcaino, J., Barahona, S., Retamales, P., Cifuentes, V., 2003. Alternative splicing of transcripts from $\operatorname{crtI}$ and $\operatorname{crt} Y B$ genes of Xanthophyllomyces dendrorhous. Appl. Environ. Microbiol. 69, 4676-4682.

Marasas, W.F., Riley, R.T., Hendricks, K.A., Stevens, V.L., Sadler, T.W., Gelineau-Van Waes, J., Missmer, S.A., Cabrera, J., Torres, O., Gelderblom, W.C., Allegood, J., Martinez, C., Maddox, J., Miller, J.D., Starr, L., Sullards, M.C., Roman, A.V., Voss, K.A., Wang, E., Merrill Jr., A.H., 2004. Fumonisins disrupt sphingolipid metabolism, folate transport, and neural tube development in embryo culture and in vivo: a potential risk factor for human neural tube defects among populations consuming fumonisin-contaminated maize. J. Nutr. 134, 711-716.

Marchler-Bauer, A., Anderson, J.B., Cherukuri, P.F., DeWeese-Scott, C., Geer, L.Y., Gwadz, M., He, S., Hurwitz, D.I., Jackson, J.D., Ke, Z., Lanczycki, C.J., Liebert, C.A., Liu, C., Lu, F., Marchler, G.H., Mullokandov, M., Shoemaker, B.A., Simonyan, V., Song, J.S., Thiessen, P.A., Yamashita, R.A., Yin, J.J., Zhang, D., Bryant, S.H., 2005. CDD: a Conserved Domain Database for protein classification. Nucleic Acids Res. 33, D192-D196.
McColl, D., Valencia, C.A., Vierula, P.J., 2003. Characterization and expression of the Neurospora crassa nmt-1 gene. Curr. Genet. 44, 216-223.

Munkvold, G.P., Desjardins, A.E., 1997. Fumonisins in maize. Can we reduce their occurrence?. Plant Dis. 81, 556-565.

OBrian, G., Fakhoury, A.M., Payne, G.A., 2003. Identification of genes differentially expressed during aflatoxin biosynthesis in Aspergillus flavus and Aspergillus parasiticus. Fungal Genet. Biol. 39, 118-127.

Parisot, D., Dufresne, M., Veneault, C., Lauge, R., Langin, T., 2002. clap1, a gene encoding a copper-transporting ATPase involved in the process of infection by the phytopathogenic fungus Colletotrichum lindemuthianum. Mol. Genet. Genomics 268, 139-151.

Pazzagli, L., Cappugi, G., Manao, G., Camici, G., Santini, A., Scala, A., 1999. Purification, characterization, and amino acid sequence of cerato-platanin, a new phytotoxic protein from Ceratocystis fimbriata f. sp. platani. J. Biol. Chem. 274, 24959-24964.

Pertea, G., Huang, X., Liang, F., Antonescu, V., Sultana, R., Karamycheva, S., Lee, Y., White, J., Cheung, F., Parvizi, B., Tsai, J., Quackenbush, J., 2003. TIGR Gene Indices clustering tools (TGICL): a software system for fast clustering of large EST datasets. Bioinformatics 19, 651-652.

Philippsen, P., Kleine, K., Pohlmann, R., Dusterhoft, A., Hamberg, K., Hegemann, J.H., Obermaier, B., Urrestarazu, L.A., Aert, R., Albermann, K., Altmann, R., Andre, B., Baladron, V., Ballesta, J.P., Becam, A.M., Beinhauer, J., Boskovic, J., Buitrago, M.J., Bussereau, F., Coster, F., Crouzet, M., D’Angelo, M., Dal Pero, F., De Antoni, A., Hani, J., et al., 1997. The nucleotide sequence of Saccharomyces cerevisiae chromosome XIV and its evolutionary implications. Nature 387, 93-98.

Proctor, R.H., Brown, D.W., Plattner, R.D., Desjardins, A.E., 2003. Coexpression of 15 contiguous genes delineates a fumonisin biosynthetic gene cluster in Gibberella moniliformis. Fungal Genet. Biol. $38,237-249$.

Pylypenko, O., Schlichting, I., 2004. Structural aspects of ligand binding to and electron transfer in bacterial and fungal P450s. Annu. Rev. Biochem. 73, 991-1018.

Quackenbush, J., Cho, J., Lee, D., Liang, F., Holt, I., Karamycheva, S., Parvizi, B., Pertea, G., Sultana, R., White, J., 2001. The TIGR Gene Indices: analysis of gene transcript sequences in highly sampled eukaryotic species. Nucleic Acids Res. 29, 159-164.

Quackenbush, J., Liang, F., Holt, I., Pertea, G., Upton, J., 2000. The TIGR gene indices: reconstruction and representation of expressed gene sequences. Nucleic Acids Res. 28, 141-145.

Sachs, M.S., Yanofsky, C., 1991. Developmental expression of genes involved in conidiation and amino acid biosynthesis in Neurospora crassa. Dev. Biol. 148, 117-128.

Shim, W.B., Woloshuk, C.P., 2001. Regulation of fumonisin B(1) biosynthesis and conidiation in Fusarium verticillioides by a cyclin-like (C-type) gene, FCC1. Appl. Environ. Microbiol. 67, 1607-1612.

Stekel, D.J., Git, Y., Falciani, F., 2000. The comparison of gene expression from multiple cDNA libraries. Genome Res. 10, 2055-2061.

Trail, F., Xu, J.R., San Miguel, P., Halgren, R.G., Kistler, H.C., 2003. Analysis of expressed sequence tags from Gibberella zeae (anamorph Fusarium graminearum). Fungal Genet. Biol. 38, 187-197.

Viaud, M., Brunet-Simon, A., Brygoo, Y., Pradier, J.M., Levis, C., 2003. Cyclophilin A and calcineurin functions investigated by gene inactivation, cyclosporin A inhibition and cDNA arrays approaches in the phytopathogenic fungus Botrytis cinerea. Mol. Microbiol. 50, $1451-1465$.

Yadav, J.S., Soellner, M.B., Loper, J.C., Mishra, P.K., 2003. Tandem cytochrome $\mathrm{P} 450$ monooxygenase genes and splice variants in the white rot fungus Phanerochaete chrysosporium: cloning, sequence analysis, and regulation of differential expression. Fungal Genet. Biol. 38, 10-21.

Yu, J., Bhatnagar, D., Cleveland, T.E., 2004a. Completed sequence of aflatoxin pathway gene cluster in Aspergillus parasiticus. FEBS Lett. 564, 126-130. 
Yu, J., Whitelaw, C.A., Nierman, W.C., Bhatnagar, D., Cleveland, T.E., 2004b. Aspergillus flavus expressed sequence tags for identification of genes with putative roles in aflatoxin contamination of crops. FEMS Microbiol. Lett. 237, 333-340.
Zhang, Z., Schaffer, A.A., Miller, W., Madden, T.L., Lipman, D.J., Koonin, E.V., Altschul, S.F., 1998. Protein sequence similarity searches using patterns as seeds. Nucleic Acids Res. 26, 39863990. 